\title{
Minimally Invasive Dental Treatment Using Composites and Ceramics in GERD Diagnoses Patients
}

\author{
ANDREI PICOS ${ }^{1 *}$, ANDREEA L. RACHISAN ${ }^{2}$, ALEXANDRA DADARLAT ${ }^{3}$ \\ ${ }^{1}$ Iuliu Hatieganu University of Medicine and Pharmacy, Department of Prevention in Dentistry, 23 Gheorghe Marinescu Str., \\ 540139, Cluj Napoca, Romania \\ ${ }^{2}$ Iuliu Hatieganu University of Medicine and Pharmacy, Clinic of Pediatrics, 23 Gheorghe Marinescu Str., 540139, Cluj Napoca, \\ Romania \\ ${ }^{3}$ Iuliu Hatieganu University of Medicine and Pharmacy, DepartmentCardiology, 23 Gheorghe Marinescu Str., 540139, Cluj \\ Napoca, Romania
}

\begin{abstract}
Specialty literature demonstrates the direct link between gastro-esophageal reflux diseases (GERD) and dental errosion (DE). Patients diagnosed with GERD often shown dental tissue loss in the enamel and dentine, somentimes going as far as opening the pulp chamber. Modern minimal invasive treatments make use of the current performance of cements and prosthetic materials (composites and ceramics) to conserve healthy enamel and dentine, in comparison to classic reconstruction methods.
\end{abstract}

Keywords: dental erosion, gastroesophageal reflux, GERD, minimally invasive dental tratment

Dentistry publications demonstrates the direct link betw een GERD and dental erosion DE [1,2]. During a high reflux episode, the salivary $\mathrm{pH}$ decreases considerably to values below 5.5, a threshold considered to be critical to enamel resistance to acid attack [3-5]. The body has the ability to neutralize acid salivary $\mathrm{pH}$ through saliva and salivary flow. These mechanisms can be influenced by various conditions such as xerostomia or drugs (antiparkinsonian, antiemetic, vitamin C, antidepressants, antihistamines) and vary from individual to individual. Intrinsic an etiology may also include bulimia, anorexia nervosa and regurgitation. Extrinsic factors are represented by a work environment that contains acid vapors, swimming and a diet, rich in acidic food and beverages [ 6 9].

Patients diagnosed with GERD show loss of dental tissue in the enamel and dentine, leading to the opening of the pulp chamber eventually. The difficulty of diagnosing DE lies in differentiating from the rest of the mechanisms leading to the loss of dental structures, the appearance being similar [10-13].

We aim to experiment certain minimally invasive modern treatment methods for dental erosions that allow dental reconstruction without the removal of healthy tissues, using the latest ceramic, composite and cement materials [14-16]. The objective is to observe their behavior for 3 years, and to make a comparison with classic, timeresistant methods but with significant tooth material sacrifices, which resultin teeth devitalization for prosthetic purposes, as well as inferior aesthetics due to metal structures used as support for the ceramic layer.

\section{Experimental part}

Based on the GERD diagnosis, ten patients with specific dental erosive lesions were selected. The evaluation of dental erosion was done by calculating the BEWE (Basic Wear Examination Index). Five patients were treated using minimally invasive methods, with ceramic and composite materials. The rest of the patients (five) were treated using classic methods, which involve the devitalization of teeth and creating metalo-ceramic crowns.
Minimally invasive modern treatment methods

Facial and intra-oral images and professional films were used in digitally planning the treatment and choosing, together with the patient, the agreed aesthetic therapeutic option. Maxillary and mandibular impressions were taken with alginate material to create study models. We also performed face-bow recording of the centric relation occlusion in the case of total rehabilitation or maximum intercuspation for the veneers, if there were stable centric stops. The vertical dimension of occlusion (VDO) for GERD patients is diminished due to tissue loss on the occlusal surface, but there is a natural compensation mechanism through egression or extrusion, which can cause difficulty in the treatment [17-20].

There are various digital software solutions that provide the clinician with various dental forms according to different types of tooth shapes, and serving as a guide for treatment planning. In the first stage, a diagnostic wax-up was done on the study models, according to the instructions given by the doctor following the facial and intra-oral analysis. The dental technician prepares the final variant with wax on the study models, called wax-up stage.

The impressions of the wax-up are made with a puttytype silicone material. A provisional material based on acrylic resin is introduced in this negative model of the final version. The impression is placed in the oral cavity and is removed after setting, the composite material remaining on the patient's teeth. Thus, the doctor and the patient obtain the mock-up, or the first preview of the final restorations. This guides the final aesthetic and functional changes. At this stage, the doctor can remove or add material to the desired areas, as well as correct the chosen colour. Subsequently, impressions of the mock up will be made to send the changes to the technician.

Minimally invasive methods uses the mock up as a guide for teeth preparations. The minimum necessary is removed to achieve the minimum thickness of the materials used (ceramics $0.3-0.5 \mathrm{~mm}$ ) and to ensure a correct emergence profile between the dental and the gingival side. After completing this step, the temporary material is removed from the teeth, thus protecting healthy tissue. The final impression will be taken with an addition

\footnotetext{
* email: andrei.picos@umfcluj.ro; Phone: 0754925804
} 
silicone material, vinyl polysiloxane, medium and light viscosity. Resin cement was used for final cementations.

Classic invasive treatment methods are restoring lost dental tissues by using metalo ceramic crowns. The metallic alloy used may be a noble (gold) or base metal ( $\mathrm{NiCr}$, titanium). Its composition makes itpossible to make strong chemical connections with the ceramic layer. The oxide layers released during burning by metals and ceramics, form a resistant chemical bond.

The retention of these prostheses is based on the mechanical preparation of the teeth. Classic preparations remove between $1 \mathrm{~mm}$ and $2 \mathrm{~mm}$ of the dental tissue in order to ensure adequate thickness of the prosthetic structure. Thus, in most cases, the dentine layer is reached, which can cause pulpitis and which has lower properties of retention, compared to enamel. Impressions are made with vinyl polysiloxane materials. Temporary crowns are made of composite materials based on acrylate. Final cementations were made using glassionomer cement for metalo ceramic crowns.

\section{Results and discussions}

The cases in question have satisfactory results, both aesthetically and functionally. It is of utmost importance to fully document the cases and follow-up. Check-ups were performed every 6 months to verify the marginal adaptation of the dental restorations, whether or not there were infiltrations at this level, the integrity and the quality of life of the patients. The five patients treated using the minimally invasive method with all-ceramic material and composites did not show marginal infiltrations, debonding, gingival retractions, color changes, and are pleased with the final appearance. The patients treated using the classic method did not present debonding, but one case had a fracture of the ceramic material, two cases had gingival retractions of $0.5 \mathrm{~mm}$, bacterial plaque accumulated at the margin of the crowns. These patients were not as aesthetically satisfied as those who received treatment using ceramic materials due to the lack of natural color and visible metallic limits in certain areas. In metalo ceramic cases when glass ionomer cement was used we found marginal infiltration after 2 years in two patients, in all ceramic and composites cases no infiltration was found. According to Magne P. and Yap AT et col. acid pH in oral cavity has negative effects on glass ionomer cements and none efect on resin cements (fig.1).

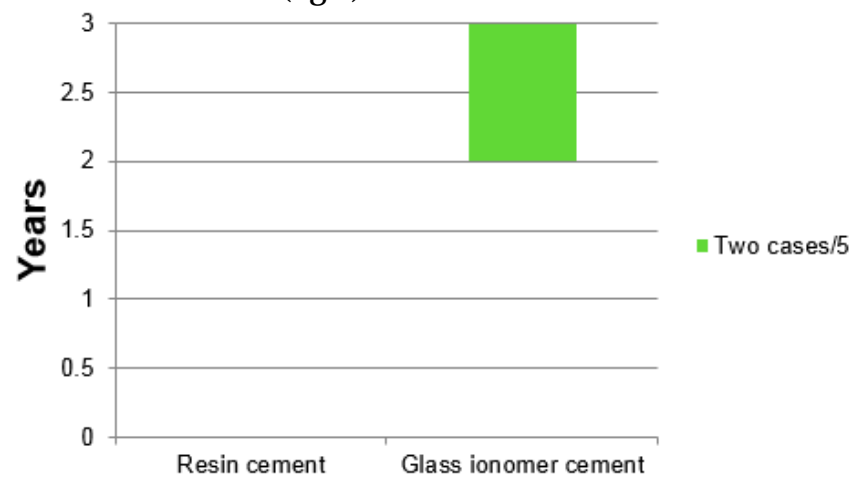

Fig. 1. Comparison between resin cement and glass ionomer cement over the course of 3 years

There are many therapeutic options described in recent years, which range from simple dental reconstruction to complex oral prosthetic rehabilitation treatments. Among these, some have been tested and accepted by the international community as a new therapeutic standard, while others still raise question marks regarding resistance over time and are considered still experimental, posing a high degree of risk.

MATERIALE PLASTICE $\bullet 55$ No. 2 • 2018

http://www.revmaterialeplastice.ro
DE is considered a growingly, worrying illness due to the increase in the number of patients diagnosed with GERD and the association of this pathology with other risk factors represented by the consumption of acidic food and beverages, certain medication, bulimia, anorexia, hyposalivation, a work environment containing acid vapours or even swimming. In most cases, new, minimally invasive treatment methods preserve the remaining dental structure intact, succeeding in restoring affected functions and providing long-term resistance of the treatment.

Modern treatment options consist of using ceramics and composites to restore lost functions. In light dental erosions, located only at enamel level, direct reconstructions with composite materials can be made. In medium and advanced tissue loss cases, where the dentine is exposed and coronary height is lost, indirect prosthetic treatments that use both composites on oclusal and palatal surfaces (palatal veneers) or ceramic material on vestibular surfaces of the anterior teeth, are necessary.

The treatment method was chosen depending on the individual particularities and the severity of the lesions. Composite and ceramic materials were used to restore affected functions, such as aesthetics, phonation, selfmaintenance and mastication.

The use of composite and ceramic materials through minimally invasive adhesives techniques as opposed to of metalo ceramic based materials, proved to be a success, both thanks to the respect for healthy dental tissue, as well as the aesthetic perception and the decreased mental discomfort as a result of less laborious and trauma due to losing more tissue during preparations. The use of digital programs has enabled more effective collaboration with the patient and its involvement in aesthetic decisions, which induce an increase in confidence in the final result.

There are different indexes for assessing the severity of the lesions, which help us in establishing a treatment plan, the most commonly used being Basic Erosion Wear Examination (BEWE). Choosing the therapeutic method varies depending on the remaining dental support and on the BEWE score, with values between 0 and 18. Minimally invasive modern treatment methods make use of the new performances of prosthetic materials (cements, ceramics, composites) to preserve enamel and dentine tissues, compared to classic methods involving invasive dental procedures.

The qualities of the resin cements used for cementing ceramic or composite structures have allowed the mechanical retention of prosthetic work to be given up (fig. 2).

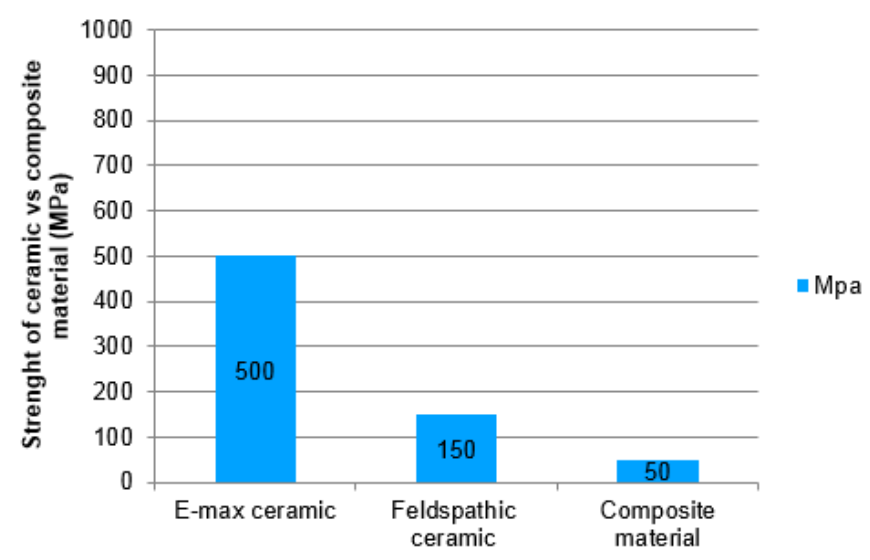

Fig. 2: Comparison between E-max ceramic, feldspathic ceramic and composite material in terms of strength (measured in $\mathrm{MPa}$ ). 
The hybrid layer formed between the dental enamel or dentine, and the prosthetic material offers superior strength, if the surfaces are prepared correctly (orthophosphoric acid for enamel, hydrofluoric acid for ceramic). The ceramic material used is E-max lithium desilicat, with a resistance to application of $500 \mathrm{MPa}$. Although the feldspathic ceramic material has a high aesthetic quality, it is especially indicated in the frontal area, having a strength of $150 \mathrm{MPa}$. Composite materials have a strength of about $50 \mathrm{MPa}$.

\section{Conclusions}

Our study confirms authors observations that glass ionomer cements are contraindicated in patients with GERD. Both types of treatment can be considered correct thanks to the restoration of lost functions and behavior over the three years. Minimal invasive treatmentmethods allow the reconstruction of teeth presenting light or average dental erosions, maintaining the integrity of the healthy dental tissue, unlike the classic option of metalo-ceramic crowns that involves advanced dental preparations and devitalization in severe tooth wear cases. Modern resin cements have a good adhesion and a strong bond between the dental surface and ceramic or composite materials, unlike the classic ones that cannot realize a hybrid layer with dental tissues. The aesthetic aspect of all-ceramic materials or even of composite materials (limited time) is superior to metalo ceramic ones that use metallic inlay core devices to assure crown retention. The gastroesophageal reflux disease is more and more often diagnosed among young people, which is why special attention needs to be paid to regular checkups and finding the first signs of erosion. At the same time, the aesthetic requirements of the patient are high, as well as the desire to preserve the integrity of the healthy tissue. Thus, the clinician is required to offer an alternative to crowns, long considered the standard treatment of severe tooth wear. Although expensive, modern treatment alternatives compensate through their natural aesthetic aspect, preserving tooth vitality and the increase of tooth survival.

\section{References}

1.LUSSI A, PORTMANN P, BURHOP B., Clin Oral Invest, 1, 1997, p. 191

2.PICOS AM, Eroziunea dentara in boala de reflux gastroesofagian Editura Iuliu Hatieganu Cluj Napoca 2014

3.PICOS AM, PICOS A, NICOARA P, CRAITOIU MM., Clujul Med., 87, nr. 4, 2014, p. 284

4.PICOS AM, LASSERRE J F, CHISNOIU AM, BERAR A, D'INCAU E, PICOS A, CHIRA A, BRULEY DE VERANNES S, DUMITRASCU DL., Human \& Veterinary Medicine International J ournal of the Bioflux Society. 7, nr. 2, 2015, p. 55

5.COLON P, LUSSI A., Br Dent J. 216, nr. 8, 2014, p. 463

6.PICOS AM, CHISNOIU AM, LASSERRE JF, SPINEI A, CHISNOIU MR, PICOS A, .Human \& Veterinary Medicine. 3, nr. 5, 2013, p. 135 7.PICOS AM, D'INCAU E, BONAFOS C, BERAR A, CHIRA A, DUMITRASCU D., Revue d'odonto stomatologie, 43, 2014, p. 56 8.LUSSI A, JAEGGI T., Clin Oral Investig, 12, nr. 1, 2008, p.5 9.D'INCAU E, SAULUI P., J. Dent. Anomalies and Orthodontics, 15, nr. 1, 2013, p. 104.

10.MILOSEVIC A., Evid Based Dent, 9. nr. 2, 2008, p. 54 11.DUNDAR A, SENGUN A., Afr Health Sci, 14, nr. 2, 2014, p. 481

12.BARTLETT D, GANB C, LUSSI A., Clin Oral Invest, 12, 2008, p. 65 13.LASSERRE J F. Recherche sur I'usure dentaire et evaluation In Vitro de biomateriaux restaurateurs avec le simulateur d' usure UVSB2. These doct, 2003, p. 23

14.PACE F, PALLOTTA S, TONINI M, VAKIL N, BIANCHI PORRO G., Aliment Pharmacol Ther, 27, 2008, p.1179

15.MOHAMED TAHIR MA, Yap AU. Oper dent., 29, 2004, p. 568

16.MAGNE, P, BELSER, U., Quintessence International, 2003, p. 336

17.0GODESCU, A.S, MARVAY, A.A, BALAN, A., GAVRILA, L, PETCU, $L$, SAVIN C. Comparative study on the effect of three disinfection procedure on streptococcus pyogenes biofilm formed on plastic materials used in paedodontics and orthodontics. Mat. Plast., 54, 2017, p. 117

18. ELSAAFIN, M., PACURAR, M., BECHIR, E.S., MARIS, M., OLTEANU, C., DASCALU, I.T, MOLDOVAN, M., Comparison of shear bond strength and adhesive remnant index of brackets bonded with two types of orthodontic adhesives. Mat. Plast., 54, 2017, p. 141 19.URACHESCU, H, PRICOP, M, BOGDAN, L, NES,C.S, PRICOP, C, RUSU, LC, RIVIS, M., Experimental compression and traction tests on heat-cured pmma used in maxillary obturator prostheses, Mat. Plast., 53, 2016, p. 76

20.GRIGORE, A, ONISEI, D, SCHILLER, E, SZUHANEK, C. The indications of poluethylene in the orthodontic field. Mat. Plast., 53, 2016, p. 227

Manuscript received: 14.01 .2018 